\title{
A UNIVERSIDADE PÚBLICA FRENTE AO CONTEXTO CONTEMPORÂNEO: EM DISCUSSÃO O CURRÍCULO E SUAS POSSIBILIDADES NA FORMAÇÃO DOCENTE
}

\author{
LA UNIVERSIDAD PÚBLICA FRENTE AL CONTEXTO CONTEMPORÁNEO: \\ EN DISCUSIÓN EL CURRÍCULO Y SUS POSIBILIDADES EN LA FORMACIÓN \\ DOCENTE
}

\author{
THE PUBLIC UNIVERSITY IN THE FRONT OF THE CONTEMPORARY \\ CONTEXT: IN DISCUSSION THE CURRICULUM AND IT'S POSSIBILITIES IN \\ TEACHER FORMATION
}

\author{
Dagmar MELLO E SILVA ${ }^{1}$ \\ Erika SOUZA LEME ${ }^{2}$ \\ Lisete JAEHN ${ }^{3}$
}

RESUMO: Considerando as demandas da sociedade contemporânea, a universidade pública e gratuita enfrenta o desafio de repensar a si própria. Portanto, é preciso tensionar a razão instrumental cristalizada na sociedade, que visa à formação para a produção de bens de consumo em detrimento da formação humana. Ao tratarmos dessas questões, faz-se necessário refletir sobre a autonomia universitária, frente à adequação curricular dos cursos de Licenciaturas ao currículo nacional gestado na Base Nacional Comum Curricular (BNCC). Pensar sob esse prisma nos ajuda a compreender os limites e as possibilidades da universidade em nosso país, especialmente da formação docente. Neste sentido, analisamos o Currículo da Faculdade de Educação da UFF, com ênfase no Componente Curricular Atividades Culturais, cujos resultados demonstram a possibilidade de se criar espaços/tempo de experiências estético-culturais críticoemancipadoras que possibilitem a formação que prioriza o Ser em detrimento do Ter.

PALAVRAS-CHAVE: Universidade pública. Autonomia universitária. Formação docente. Currículo. Formação cultural.

\footnotetext{
${ }^{1}$ Universidade Federal Fluminense (UFF), Niterói - RJ - Brasil. Docente na Faculdade de Educação. Docente do Curso de Mestrado em Diversidade e Inclusão e Colaboradora do Programa de Pós-graduação de Comunicação, mídias e cotidiano. ORCID: https://orcid.org/0000-0002-5863-3607. E-mail: dag.mello.silva@gmail.com

${ }^{2}$ Universidade Federal Fluminense (UFF), Niterói - RJ - Brasil. Docente na Faculdade de Educação. Coordenadora do Projeto de Extensão - SIGPROJ: Formação Cultural e Educação Inclusiva- ampliando horizontes e diminuindo barreiras. ORCID: http://orcid.org/0000-0002-8088-6002. E-mail: erika.leme10@gmail.com

${ }^{3}$ Universidade Federal Fluminense (UFF), Niterói - RJ - Brasil. Docente na Faculdade de Educação. Líder do Grupo de Estudos e Pesquisas em Currículo, Culturas e Formação de Professores (CCFP). Membro e Vice-Líder do Formar - Grupo de Pesquisa em Formação e Práticas Pedagógicas e do Núcleo de Didática e Formação de Professores. ORCID: https://orcid.org/0000-0002-1208-4577. E-mail: lisetej@gmail.com
} 
RESUMEN: Considerando las demandas de la sociedad contemporánea, la Universidad pública y gratuita enfrenta el desafío de repensarse a sí misma. Por lo tanto, es necesario reconocer la razón instrumental cristalizada en la sociedad, que tienen por objetivo la formación para la producción de bienes de consumo en detrimento de la formación humana. Al tratar estas cuestiones, se hace necesario reflexionar sobre la autonomía universitaria, en contra de la adecuación curricular de los cursos de pregrado al currículo nacional desarrollado en la Base Común Nacional Curricular (BNCC). Pensar bajo ese prisma nos ayuda a comprender los limites y las posibilidades de la Universidad en nuestro país, específicamente de formación docente $y$, en este sentido, analizamos del currículo de la facultad de Educación de la Universidad Federal Fluminense (UFF), con énfasis el componente curricular Actividades Culturales, cuyos resultados emuestran la posibilidad de crear espacios/tiempos de experiencias estético-culturales critico-emancipadoras que permiten la formación que prioriza el Ser en detrimento del Tener.

PALABRAS CLAVE: Universidad púbica. Autonomía universitaria. Formación docente. Currículo. Formación cultural.

ABSTRACT: Considering the demands of the contemporary society, the public and cost-free University faces the challenge of rethinking itself. Therefore, it is necessary to recognize the instrumental reason crystallized in society, which aims at training for the production of consumer goods to the detriment of human education. In dealing with these issues, it is necessary to reflect on the university autonomy, against the curricular adequacy of the undergraduate courses to the national curriculum developed in the National Curricular Commom Base (BNCC). Thinking under that prism helps us to understand the limits and possibilities of the University in our country, specifically teacher training, and, in this sense, we analyze the cuuriculum at Federal Fluminense University (UFF), with emphasis on the curricular component Cultural Activities, whose results demonstrate the possibility of creating spaces/times for enabling aesthetic-cultural critical-emancipatory experiences that allow the formation that prioritizes the Being to the detriment of the Having.

KEYWORDS: Public University. University Autonomy. Teacher Formation. Curriculum. Cultural Education.

\section{Introdução}

Damos início a essa escrita expondo nossas reflexões a partir de nossas próprias experiências como professoras e gestoras da Faculdade de Educação da Universidade Federal Fluminense, portanto, o texto que se desvela pela frente, prescinde das usuais revisões bibliográficas, para lançar mão de saberes que não só foram construídos na empiria de nossas atuações, mas, e principalmente, sob a estética de nossas experiências, no sentido benjaminiano que esta palavra propõe, ou seja, como um narrador, aquele que "figura entre os mestres e sábios" [...] pois pode recorrer ao acervo 
de toda uma vida". Ou seja, aquele que ao inserir uma utilidade prática naquilo que narra, "não conta apenas com a experiência própria, mas lhe acrescenta muito da alheia. [...] assimila ao seu próprio saber, também, aquilo que aprendeu com o que ouviu de outros [...]" (BENJAMIN, 1994, p. 220-221).

No entanto, destacamos, que não se trata de abandonar a sistematização do pensamento, necessária a produção do conhecimento científico. Ao invocarmos o conceito de experiência trazendo à luz o narrador, “[...] não significa trazê-lo mais perto de nós, e sim, pelo contrário, aumentar a distância que nos separa dele. Vistos de uma certa distância, os traços grandes e simples que caracterizam o narrador se destacam nele. (IDEM, p. 197). Dito isto damos continuidade ao foco de nossa escrita que procura problematizar os modos como as políticas de verdade, instituem formas dominantes de ideias instrumentais que embotam as possibilidades de se criar espaços/tempo de experiências estético-culturais, crítico-emancipadoras que possibilitem a formação que prioriza o Ser em detrimento do Ter.

Já se tornou lugar comum discursos em defesa da educação que atribuem um valor redentor e de ascensão social às instituições educacionais de um modo geral e à universidade, em especial. Boa parte dos levantamentos das mídias relacionados ao desempenho do ensino superior enfatizam, em suas análises, um caráter instrumental, voltado para o mercado de trabalho, buscando enfatizar questões sobre quais possibilidades uma carreira ou um determinado curso pode oferecer em termos de empregabilidade. Como alinhar a escolha de um curso (tomando como referência o mercado de trabalho) às expectativas dos discentes ${ }^{4}$ ?

Caminhando na esteira do pensamento de Michel Foucault e suas análises a respeito das práticas de subjetivação próprias de cada tempo, somos levadas a concluir que esse caráter instrumental dado ao ensino superior está imbricado com perspectivas culturais, econômicas e sociais de nosso tempo. Sob essa perspectiva fica fácil entender,

\footnotetext{
${ }^{4}$ Um levantamento em quatro capitais brasileiras mostrou que $8 \%$ dos adolescentes acham importante entrar na faculdade "porque é o sonho dos pais". O dado é um dos resultados de pesquisa que avaliou o que esperam pais e alunos após a conclusão do ensino médio. A pesquisa foi realizada pela consultoria Educa Insigths, encomendada pela Associação Brasileira de Mantenedoras de Ensino Superior (ABMES). Foram entrevistadas 1,2 mil pessoas nas cidades de São Paulo, Rio de Janeiro, Salvador e Porto Alegre. $\mathrm{Na}$ perspectiva dos alunos, a justificativa mais constante para cursar o ensino superior é "conseguir um bom emprego no futuro", apontado por $66 \%$ dos entrevistados. Na sequência aparece, com $31 \%$, a resposta "porque é importante para mim", seguida de "porque é exigido pelo mercado de trabalho", com $28 \%$, e "porque sempre sonhei com isso", com 20\%. Entre os adolescentes, a maioria (60\%) já decidiu qual curso pretende seguir. Os cursos tradicionais aparecem como as principais escolhas daqueles que já escolheram. Fonte: https://abmes.org.br/noticias/detalhe/2101/pesquisa-abmes-maior-parte-dos-alunosnao-ingressa-na-universidade-por-falta-de-dinheiro.
} 
genealogicamente, como esses discursos se constituem e suas atuações como mecanismos de manutenção e controle necessários para a formação dos indivíduos em sociedades cujas economias e políticas estão submetidas aos desmandos do capital.

No enfrentamento dessas questões, esse artigo tensiona o papel da universidade pública numa sociedade plural, democrática e altamente tecnificada, defendendo-se que essa instituição deve ser o espaço-tempo da inventividade de uma formação cultural que perpassa o mundo do trabalho, voltada para todas as dimensões humanas, tal como defendido por Anísio Teixeira (1988, p. 17):

A função da universidade é uma função única e exclusiva. Não se trata, somente, de difundir conhecimentos. O livro também difunde. Não se trata, somente, de conservar a experiência humana. O livro também os conserva. Não se trata, somente de preparar práticos ou profissionais, de ofícios ou artes. A aprendizagem direta os prepara, ou, em último caso, escolas muito mais singelas do que as universidades. Trata-se de manter uma atmosfera de saber pelo saber para se preparar o homem que serve e o desenvolve. Trata-se de conservar o saber vivo e não morto, nos livros ou no empirismo das práticas não intelectualizadas. Trata-se de formular intelectualmente a experiência humana, sempre renovada, para que a mesma se torne consciente e progressiva.

Todas essas funções se fundem de tal modo que a constituição da universidade é, de alguma forma, a história da humanidade, pois, tem como pressuposto o ensino atrelado às realidades locais e voltado para as demandas sociais, sobretudo, humanas. Daí, a defesa de Teixeira (1988, p. 18) de que a "universidade é e deve ser a mansão da liberdade".

Entretanto, a universidade é o espelho da sociedade e, portanto, reflete suas contradições. Logo, defender a universidade na perspectiva da lógica capitalista é assumir que o conhecimento produzido passa a ser mercadoria e que o acesso se dará somente por aqueles que puderem comprá-lo.

Tal conjuntura explicita uma crise ética, em âmbito global, que nos requisita pensar nossa caminhada civilizatória e os paradigmas que nortearam nossas práticas sociais. Diante desse cenário, nos deparamos com o fortalecimento dos processos de exclusão sobre as conquistas que poderiam culminar em uma sociedade justa e inclusiva. Assim, presenciamos o ressurgimento de movimentos raciais, nacionalistas, religiosos, xenófobos, misóginos, homofóbicos e racistas, de caráter fundamentalista, 
dando suporte a políticas que resultam em discriminação racial, sexual, política e religiosa sob argumentos em defesa de uma suposta "tradição familiar".

Outrossim, fecham-se as fronteiras para as migrações de indivíduos, famílias e coletividades, produzindo pobreza e fome em nome da defesa territorial. Vivemos sob uma lógica em que o capital se sobrepõe ao trabalho. O mercado e a propriedade se tornam prioridade frente aos direitos sociais básicos, fatores que geram o desemprego cíclico e estrutural, o subemprego e a exploração da força de trabalho, promovendo o crescimento de contingentes populacionais que vivem em condições precárias, na linha da miséria.

Talvez estejam aí as razões pelas quais discursos que atribuem à Universidade uma função instrumental e tecnicista, de redenção social, ganhem força e produzam efeitos na subjetividade de estudantes universitários. Esses discursos atuam naquilo que Bauman (2008) considera como marcas dos tempos atuais, ou seja, o medo e a insegurança diante de um futuro que não permite boas expectativas.

Temos medo da violência urbana, do desemprego, das epidemias, do terrorismo, enfim de tudo aquilo que a sociedade capitalista produziu e que descambou em processos de exclusão. Como consequência, buscamos, incansavelmente, na atuação profissional uma saída "capital" para não "cairmos" no abismo da exclusão de uma alteridade que tememos assumir como nossa. Quanto a isso, Bauman (2008) nos fala do medo da 'morte de segundo grau'. Aqui a morte não é física, mas sim, uma metáfora das separações, perdas, exclusões, rupturas que vivenciamos ao longo da vida. A este temor o autor denomina 'contos morais' de nossa época, o temor da eliminação e da impotência diante de um destino adverso que nos afasta de relações comunais, reificando o individualismo. Cabe aqui a imagem do Angellus Novus pintado por Paul Klee sob uma interpretação singular de Walter Benjamin (1994, p. 226):

Há um quadro de Paul Klee que se chama Angelus Novus. Representa um anjo que parece querer afastar-se de algo que ele encara fixamente. Seus olhos estão escancarados, sua boca dilatada, suas asas abertas. O anjo da história deve ter esse aspecto. Seu rosto está dirigido para o passado. Onde nós vemos uma cadeia de acontecimentos, ele vê uma catástrofe única, que acumula incansavelmente ruína sobre ruína e as dispersa a nossos pés. Ele gostaria de deter-se para acordar os mortos e juntar os fragmentos. Mas uma tempestade sopra do paraíso e prende-se em suas asas com tanta força que ele não pode mais fechálas. Essa tempestade o impele irresistivelmente para o futuro, ao qual ele vira as costas, enquanto o amontoado de ruínas cresce até o céu. Essa tempestade é o que chamamos progresso. 
Essa imagem do pensamento de Walter Benjamin expressa a crise moral no mundo contemporâneo, crise esta que se afasta cada vez mais de uma perspectiva ética: relevam-se os erros de ontem para que se cometam novos erros, mesmo que estes sacrifiquem a possibilidade de um amanhã mais ético, nos (des)orientando para trajetos que ilusoriamente nos ofereçam maior segurança diante das incertezas que nos assombram. O sujeito moral no mundo contemporâneo torna-se uma pessoa tão preocupada com seus próprios anseios que não lhe sobra tempo para ver as barbáries que são cometidas a um outro que não lhe é tão próximo. Daí o caráter instrumental assumir o protagonismo em nossa cultura.

A cultura líquido-moderna não se sente mais uma cultura da aprendizagem e da acumulação, como as culturas registradas nos relatos de historiadores e etnógrafos. Em vez disso, parece uma cultura do desengajamento, da descontinuidade e do esquecimento (BAUMAN, 2013, p. 37).

Tais considerações revelam a racionalidade instrumental legitimada por saberespoderes que se julgam no direito de dominar e modificar o meio físico e consequentemente, a vida, através dos avanços tecno-científicos que operam em favor do capital, em detrimento da vida planetária.

Diante do exposto, indagamos: a quem ou a que se destina o discurso que atribui às instituições formativas o sentido instrumental, no qual jovens devem contar unicamente com seus esforços e com sua capacidade de trabalho para que possam se assegurar socialmente?

Deveras essa racionalidade a que temos servido na produção acadêmica do conhecimento, nos ajudou, em muito, para alcançar o desenvolvimento tecnológico e as "certezas" do tempo atual, mas, não apresentou saídas para as cegueiras que domesticam a vida, colocando-a à serviço do capital. Portanto, "[...] de que valeria a obstinação do saber, se ela assegurasse apenas a aquisição dos conhecimentos e não o descaminho daquele que conhece? [...] de que maneira e até onde seria possível pensar diferentemente em vez de legitimar o que já se sabe?" (FOUCAULT, 1984, p. 14).

Frente ao que está posto socialmente, Teixeira (1988, p. 17) problematiza que "a universidade não tem nenhuma 'verdade' a dar, a não ser a única possível, que é a de buscá-la eternamente”. Contudo, como isso será possível numa sociedade cada vez mais regulada, tal como é a sociedade contemporânea? 


\section{A autonomia universitária: desafios e possibilidades}

Historicamente a Universidade tem assumido para si a tarefa de transmissão de saberes e verdades cientificamente consolidadas. Porém, ao optar por um certo tipo de razão ou conhecimento científico, limitou seu olhar para um modo operante "verdadeiro" e "objetivo" de entendimento das "coisas" do mundo, despojando-se da formação intelectual a educação político-sentimental que integra a formação cultural ${ }^{5} \mathrm{e}$ que poderia criar as condições para ações emancipadas que nos permitem questionar "um conjunto de regras e coerções características, [...] um certo tipo de discurso científico numa época dada; [...] dotado de efeitos específicos de coerção ou simplesmente de incitação do que é validado como científico, racional ou comumente recebido" (FOUCAULT, 1990, p. 49).

Em geral, preocupados com as demandas de conteúdo explícitas nos currículos de seus cursos, professores e alunos reproduzem um modelo de episteme que acaba por reafirmar a sociedade na qual esse currículo se organiza, numa simbiótica relação entre conhecimento e culturas, a produzir uma regulação social do currículo (POPKEWITZ, 1997). O currículo é, assim, uma seleção cultural determinada que traduz um modelo educativo. Numa sociedade liberal e capitalista, como a nossa, o currículo tenderá a garantir a reprodução de um conjunto de valores sociais, econômicos e políticos que atendam a este modelo social, produzindo-se, em geral, uma regulação social conservadora.

Contudo, há tempos sabemos que o currículo é um campo de disputas e que a proposição das políticas de currículo e a sua materialização não é um processo linear. Tanto a proposição de uma política quanto a sua execução são terrenos disputados. Portanto, ao falarmos de currículo nunca teremos garantias, tal como as teorias curriculares tradicionais preconizavam, pelo simples fato de estarmos lidando com campos de forças que não convergem - diferentes projetos de sociedade e, consequentemente, diferentes concepções sobre currículo - e condições de aprendizagem bastante heterogêneas. Neste sentido, é plausível questionar como a

\footnotetext{
${ }^{5}$ Para aprofundamento sobre o conceito de Formação Cultural indicamos: JAEHN, L. Semi-formação e Formação Cultural. ETD - Educação Temática Digital, Campinas, v. 10, n. 1, p. 114-132, dez. 2008; LEME, E. S.; COSTA, V. A. da. Formação estético-cultural no pensamento de Theodor W. Adorno: a reflexão crítica e o desenvolvimento da sensibilidade. Revista Estética. Universidade de São Paulo Escola de Comunicações e Artes, v. 2, p. 1 - 14, 2015.
} 
regulação social é produzida dentro e fora da escola, pelo Estado, pelas políticas neoliberais, mas, também a partir do próprio discurso pedagógico (JAEHN, 2014).

Se considerarmos que um currículo é feito de escolhas que nos levam a priorizar alguns conteúdos em detrimento de outros, fica evidente a estreita relação entre currículo e conhecimento como prática discursiva de poder. Nas pistas de Foucault, Popkewitz (2001) mostra como o conhecimento pedagógico (curricular) é um elemento constitutivo e material do mundo contemporâneo, no qual os conhecimentos curriculares constituem sistemas discursivos que formam padrões de conhecimento que incorporam um contínuo de valores e produzem normas e divisões linguisticamente produzidas.

Logo, na governamentalidade neoliberal o currículo se torna meio de legitimação para a formação de capital humano competente, hábil e flexível, sendo que esta flexibilidade está longe de uma condição criadora. As contínuas exigências de reformulação curricular no que tange aos objetivos e à avaliação evidenciam práticas miméticas para que o controle pedagógico possa acompanhar e atender a um modelo de sociedade líquida que se amalgama e se desfaz segundo as demandas do mercado.

No contexto atual da formação docente vivemos dois cenários que colocam em xeque a autonomia universitária: as tentativas de controle financeiro e ideológico por parte do governo central e a adequação curricular dos cursos de Licenciaturas ao currículo nacional gestado na Base Nacional Comum Curricular (BNCC), que está em fase de implantação em todo o país. É este segundo ponto que gostaríamos de destacar aqui, especialmente.

Para além de questionar o que está na base da Base, é necessário olhar para as experiências curriculares internacionais para compreender como um currículo nacional e uma avaliação padronizada afetam a autonomia da instituição escolar e do próprio docente, produzindo-se consequências como: a demonização dos professores que são culpados pelos resultados objetivos não alcançados, os riscos para a democracia numa educação voltada para resultados, a perda de autonomia dos cursos de formação de professores e a desumanização do trabalho docente (AGUIAR; DOURADO, 2018).

Contrariando a necessidade de se ter uma intervenção central via currículo, para Macedo (2018, p. 31), "não é inexorável que políticas públicas, para serem públicas e lidarem, por exemplo, com a educação de todo o país, tenham que produzir respostas centralizadas; elas podem ser gestadas nos espaços-tempo em que as intervenções acontecem". A autora defende algo que nós reiteramos, de que as políticas curriculares 
podem ser pensadas na escola ou na Universidade, desde que se tenha professores valorizados e financiamento educacional à altura das necessidades estruturais da instituição de ensino. No caso brasileiro, ambas as condições inexistem. A escolha que a política curricular faz, neste momento, é de articular o processo educacional ao desenvolvimento de objetivos educacionais voltados para o desenvolvimento de competências, enfatizando-se aquelas de ordem técnica em detrimento de um desenvolvimento integral que pudesse levar a uma formação cultural. Ou seja, ratificase uma educação voltada para resultados relacionados às principais áreas de interesse do mercado e das avaliações internacionais, como o Programa Internacional de Avaliação de Estudantes (PISA), por exemplo.

De certo modo, reduzir o currículo ao desenvolvimento de competências pode ser uma forma de assegurar ao professor um certo modo de fazer, mas, reforça a crença equivocada de que é possível ensinar tudo a todos ao mesmo tempo e no mesmo ritmo. Ignora os diferentes tempos e condições de aprendizagem dos indivíduos, contrastando, especialmente, com as instabilidades e incertezas que a contemporaneidade nos oferece. Estes são também os argumentos de uma educação maior, de uma educação tradicional que acredita em critérios meritocráticos que pautam os currículos e as ações pedagógicas a partir de (pré) textos que se articulam em esferas governamentais de políticas e planos de educação marcados "por uma heteronomia e por práticas de assujeitamento, (GALLO, 2006, p. 78), assumindo uma perspectiva educacional empreendedora, ou seja, da Educação como investimento econômico. Reduz-se, assim, a educação a uma qualificação que prepara para a competitividade necessária à reestruturação produtiva e a empregabilidade dos tempos atuais.

Essas considerações foram realizadas para que se possa dar a ver a importância de compreendermos que os discursos se constituem por elementos significantes que remetem a conteúdos ou a representações como práticas que conformam os objetos sobre os quais falam. "Certamente os discursos são feitos de signos; mas o que fazem é mais que utilizar esses signos para designar coisas. É esse mais que os torna irredutíveis à língua e ao ato da fala. É esse 'mais` que é preciso fazer aparecer e que é preciso descrever" (FOUCAULT, 1986, p. 56).

Pensar sob esse prisma nos ajuda a compreender como o currículo é um potente instrumento de poder. Portanto, problematizar as práticas discursivas curriculares expressas em "elementos significantes" é uma tarefa necessária para que possamos entender quais relações de poder-saber estão implícitas e atravessam esses discursos. 
Trata-se de revelar as condições de funcionamento de um discurso mostrando as suas formas de:

[...] impor aos indivíduos que os pronunciam certo número de regras e assim de não permitir que todo mundo tenha acesso a eles [...] ninguém entrará na ordem do discurso se não satisfazer a certas exigências ou se não for, de início, qualificado para fazê-lo. [...] o ritual define a qualificação que devem possuir os indivíduos que falam [...] enfim, a eficácia suposta ou imposta das palavras, seu efeito sobre aqueles aos quais se dirigem, os limites de seu valor de coerção (FOUCAULT, 2008, p. 37-39).

Nessa perspectiva, Silvio Gallo (2012) nos ajuda a pensar uma educação em linhas menores, por vias inventivas e criativas, atenta às singularidades entre professores e alunos. Uma educação menor não possui prescrição, pois se produz por intensidades que promovem desterritorializações que descentralizam os sedentarismos para quebrar a imagem dogmática da instituição escolar, por vias inventivas, escapando do controle estatal de políticas educacionais que estabelecem os critérios e finalidades do que deve estar no centro do ensino. É essa educação menor que nos importa pensar e construir hoje.

Trata-se de reiterar e reforçar a autonomia da Universidade pública, assim como da escola e dos docentes ao invés de extirpá-la. Reforçando a afirmação de Lopes (2018, p. 26), nós já temos currículo e "não é necessário que todas as escolas tenham o mesmo currículo: o currículo precisa fazer sentido e ser construído contextualmente, atender demandas e necessidades que não são homogêneas". Não se trata de não haver direcionamento, tal como acontecia nas Diretrizes Curriculares Nacionais, mas, de não haver condicionamento, assim como uma educação para as competências técnicas sugere, nas suas entrelinhas.

Defendemos que o caráter salvacionista que a BNCC pretende imprimir é uma retórica falaciosa diante das desigualdades do sistema educativo quanto à carreira docente e as precárias condições de trabalho nas instituições escolares, inclusive nos cursos de formação de professores das Universidades públicas. Trata-se de uma ordenação do discurso que busca ocultar os interesses econômicos que estão na base da Base, especialmente do mercado editorial e das assessorias educacionais. 


\title{
O currículo de Pedagogia da FEUFF e a Formação cultural: possibilidades para o livre pensar
}

Considerando a concepção de Universidade defendida por Teixeira (1988, p. 17), a qual se constitui como lugar “[...] de saber facilitador da participação de todos na formação intelectual da experiência humana", voltamo-nos às possibilidades do currículo do curso de Pedagogia da Faculdade de Educação da Universidade Federal Fluminense (FEUFF). Nesse sentido, a fim de compreendermos a envergadura deste curso de pedagogia em relação à possibilidade da 'formação intelectual da experiência humana', nos debruçamos sobre o componente curricular Atividades Culturais, tendo em vista que:

\begin{abstract}
As Atividades Culturais são uma proposta original e exclusiva do currículo de Pedagogia da UFF, já desde o Projeto Pedagógico do Curso de 1993. Buscam contribuir para o aprimoramento da formação geral e profissional dos estudantes e, fugindo do formalismo das disciplinas de nomenclaturas e conteúdos específicos, constituem-se como espaços de experienciação e aprendizagem de temas culturais os mais diversos - que possam atualizar e ampliar a visão do pedagogo sobre o mundo, desenvolvendo sua sensibilidade estética, tanto na fruição como na expressão. Anteriormente, esse componente curricular não possuía o qualificativo "cultural", apenas denominando-se Atividades. Nos anos de trabalho de prática do currículo anterior, esse componente curricular definiu-se melhor, tendo sido enfatizado o aspecto cultural das temáticas oferecidas. São temas voltados para a arte (literatura, pintura, teatro, cinema, música etc.), o patrimônio cultural, bem como fazeres do tipo oficinas, viagens e passeios (CURSO DE PEDAGOGIA, 2018, p. 6).
\end{abstract}

A existência deste componente curricular vai ao encontro do conceito de formação cultural defendido por Adorno (2010), que se contrapõe veementemente à consciência reificada que cerceia as possibilidades de ser e estar no mundo. Nesta perspectiva, a humanidade está sujeita à adesão da sujeição na formação socialmente determinada.

As consequências de uma formação incompleta e especializada são facilmente identificadas na personalidade do indivíduo, que tende, por um lado, a se concentrar em torno de poucos interesses, sentindo dificuldades para resolver os problemas ou enfrentar situações que vão além destes. Por outro lado, esta atitude também dificulta a comunicação entre as pessoas, na medida em que cada um se concentra no seu próprio mundo, demonstrando-se alheio, desinteressado e intolerante com todos os que estão fora dele. (JAEHN, 2008, p. 120). 
Assim, em oposição à formação social da contemporaneidade, denominada por Adorno (2005) de pseudoformação, é preciso tensionar a cultura e a formação para trazer à tona seus momentos constitutivos da consciência emancipadora. Nesse sentido, a formação para ser emancipadora é crítica à pseudoformação, resistente à sociedade reprodutora pautada no dueto produzir e consumir e reveladora das contradições sociais. Portanto, no contexto atual, a dinâmica da formação cultural deveria, pois, corresponder a "uma sociedade de seres livres e iguais, de uma forma pura, indicando assim uma sociedade sem classes e sem exploração" (ADORNO, 2005, p. 4). Uma vez que:

A formação cultural é justamente aquilo para o que não existem à disposição hábitos adequados; ela só pode ser adquirida mediante esforço espontâneo e interesse, não pode ser garantida simplesmente por meio da frequência de cursos [...]. Na verdade, ela nem corresponde ao esforço, mas sim à disposição aberta, à capacidade de se abrir a elementos do espírito, apropriando-os de modo produtivo na consciência, em vez de se ocupar unicamente para aprender, conforme prescreve um clichê insuportável (ADORNO, 2010, p. 64).

Considerando a formação cultural como possibilidade de desnaturalizar e problematizar criticamente a própria cultura, problematizamos o processo de formação docente, a fim de que se amplie a percepção da sociedade, da vida humana e da condição do próprio indivíduo, com vistas a romper com a frieza presente nas relações de trabalho e a aridez do espírito.

Nesta perspectiva, Adorno (2010) defende a instituição escolar como sendo o lugar para desenvolver o espírito e o objetivo da educação como sendo o de permitir e desenvolver experiências formativas. Por sua vez, o processo formativo de professores demanda, na contemporaneidade, se contrapor ao isolamento na sala de aula, à concepção restrita de que somente os conteúdos escolares são relevantes, posto que:

\begin{abstract}
A formação cultural é a possibilidade da libertação individual dos mecanismos coercitivos da socialização e da imposição coisificadora da 'desenfreada economia de mercado' [...] sobre a cultura e a consciência. Porém, esta possibilidade da libertação individual não deve se tornar objetivo final, mas deve ser entendida como pressuposto incondicional para a humanização da práxis social (SCHMIED-KOWARZIK, 1983, p. 112).
\end{abstract}

A relevância desse processo formativo se revela no pensamento de Teixeira (1988, p. 37), quando afirma que, “[...] nenhum país do mundo, até hoje, julgou possível construir uma cultura de baixo para cima, dos pés para a cabeça. Para haver primário, é 
necessário que exista antes o secundário e para que o secundário funcione é preciso que existam universidades", cuja autonomia e o livre pensar estejam de mãos dadas.

Nesta conjuntura, os desdobramentos da formação cultural são incalculáveis, seja na escola de educação básica ou nas universidades, pois podem significar uma potente oportunidade de alargamento do horizonte e de fortalecimento do espírito, ou seja, além de propiciar, de maneira crítica, o contato com as culturas em suas diversas manifestações, pode ampliar o seu horizonte cultural bem como a capacidade de relacionar os conteúdos das diversas áreas do conhecimento com a vida humana.

Assim, com vistas a visualizarmos a estrutura curricular deste componente curricular, elaboramos a tabela 1, que explicita as possibilidades de formação docente expressas no currículo da Faculdade de Educação da Universidade Federal Fluminense - FEUFF, no ano de 2018/2, a saber:

Tabela 1 - As Atividades Culturais da Matriz Curricular de Pedagogia da UFF de $2018 / 2$

\begin{tabular}{|c|c|c|}
\hline Período & $\begin{array}{l}\text { Componente } \\
\text { curricular } \\
\text { obrigatório }\end{array}$ & Tema das atividades \\
\hline \multirow[t]{5}{*}{$\mathbf{1}^{\mathbf{o}}$} & \multirow{5}{*}{$\begin{array}{l}\text { ATIVIDADES } \\
\text { CULTURAIS - I }\end{array}$} & Arte, Educação da Atenção e Silêncio Contemplativo \\
\hline & & Cinema e Educação: "muito para aprender" \\
\hline & & $\begin{array}{l}\text { Bem-estar no campus: uma exploração sensorial, institucional } \\
\text { e relacional }\end{array}$ \\
\hline & & Tecnologias de Informação e Comunicação e Educação \\
\hline & & Produção de Materiais bilíngues para surdos \\
\hline \multirow[t]{3}{*}{$3^{\mathbf{o}}$} & \multirow{3}{*}{$\begin{array}{c}\text { ATIVIDA DES } \\
\text { CULTURAIS - II } \\
60 \mathrm{~h}\end{array}$} & Brincantes: Brinquedos \& Brincadeiras na Formação Humana \\
\hline & & Cinema Crítico e Educação \\
\hline & & As peças didáticas de Brecht: Teatro Político e Educação \\
\hline \multirow[t]{2}{*}{$5^{\mathbf{0}}$} & \multirow{2}{*}{$\begin{array}{c}\text { ATIVIDA DES } \\
\text { CULTURAIS - III } \\
60 \mathrm{~h}\end{array}$} & Literatura Brasileira Modernista \\
\hline & & $\begin{array}{l}\text { Educação em Espaços de Privação de liberdade: gênero, raça } \\
\text { e desigualdades socioeducacionais }\end{array}$ \\
\hline $7^{\mathbf{o}}$ & $\begin{array}{c}\text { ATIVIDA DES } \\
\text { CULTURAIS - IV } \\
60 \mathrm{~h}\end{array}$ & Formação Cultural: em discussão Bullying e preconceito \\
\hline \multirow[t]{3}{*}{$9^{\mathbf{0}}$} & \multirow{3}{*}{$\begin{array}{c}\text { ATIVIDA DES } \\
\text { CULTURAIS - V } \\
60 \mathrm{~h}\end{array}$} & $\begin{array}{l}\text { Crônicas e contos de autores brasileiros e estrangeiros e } \\
\text { Educação }\end{array}$ \\
\hline & & Encontro de Saberes I \\
\hline & & Encontro de Saberes II \\
\hline
\end{tabular}

Fonte: autores

Reconhecendo o componente curricular de Atividades Culturais como elo fundamental à Formação Cultural, vale destacar que se situa ao longo de todo o curso, afim de propiciar uma experiência mais consistente e, por conseguinte, uma visão crítica 
sobre as culturas, bem como incentivar aos alunos a frequentarem os espaços e eventos culturais oferecidos pela Universidade e na sociedade ao longo do tempo de permanência na instituição, para a ampliação do repertório cultural dos mesmos. De modo que:

Quanto mais facetada se cultiva a receptividade, quanto mais móvel é, quanto mais superfície oferece aos fenômenos, tanto mais mundo o homem capta, tanto mais disposições ele desenvolve em si; quanto mais força e profundeza ganha sua personalidade, quanto mais liberdade ganha sua razão, tanto mais mundo o homem concebe, tanto mais forma cria fora de si. Sua cultura consistirá, pois, no seguinte; primeiro: proporcionar à faculdade receptiva os mais multifacetados contatos com o mundo e elevar ao máximo a passividade do sentimento; segundo: conquistar para a faculdade determinante a máxima independência com relação à receptiva e ativar ao extremo a atividade da razão. Quando as duas qualidades se unificam, o homem conjuga a máxima plenitude de existência à máxima independência e liberdade, abarcando o mundo em lugar de nele perder-se e submetendo a infinita multiplicidade dos fenômenos à unidade de sua razão (SCHILLER, 1990, p. 64).

Ao abranger esferas mais amplas da educação, afirma-se a relação entre o conhecimento, a sociedade e a vida do indivíduo. Indo ao encontro do pensamento de Kant (2003, p. 57), "La parte positiva de la educación es la cultura. El hombre se distingue por ella del animal. Consiste, sobre todo, em el ejercicio de las facultades de su espíritu". Nesse sentido, vale destacar o pensamento de Adorno, nas palavras de Maar (In. ADORNO, 2010, p. 14), “Adorno combate em uma dupla frente: a um tempo contra a 'falsa cultura' e a favor da 'cultura"':

\footnotetext{
Quando o espírito não realiza o socialmente justo, a não ser que se dissolva em uma identidade indiferenciada com a sociedade, estamos sob o domínio do anacronismo: agarrar-se com firmeza à formação cultural, depois que a sociedade já a privou de base. Contudo, a única possibilidade de sobrevivência que resta à cultura é a autorreflexão crítica sobre a semiformação (pseudoformação), em que necessariamente se converteu (ADORNO, 2005, p. 18).
}

A crítica adorniana ilumina a dimensão genuína da formação que é a emancipação, ou seja, propiciar condições ao indivíduo de desenvolver sua autonomia para que ele não reproduza e não se submeta ao mundo que o circunscreve.

Nesse sentido, a faculdade em tela demonstra resistência à adaptação per si, pois, como pudemos observar na tabela 1, o curso dispõe de 270 horas de Atividades Culturais, o que é bastante diante dos limites sociais que se interpõem ao processo de 
formação. Tal constatação é impactante por valorizar o processo de formação docente, sobrepujando as formas reducionistas de formação. Citando Schelling, Adorno e Horkheimer (1985, p. 29) enfatizam que "a arte entra em ação quando o saber desampara os homens. Para ele [Schelling], a arte é 'o modelo da ciência e é aonde está a arte que a ciência deve ainda chegar". Portanto, o Componente Curricular de Atividades Culturais se apresenta como um caminho fecundo para possibilitar a formação crítica, ética, política, filosófica, psicológica, humana, sensível e inclusiva, na medida em que objetiva "contribuir para uma formação profissional que desenvolva, integre e harmonize razão e sensibilidade, oportunizando contatos com produções artísticas e culturais diversificadas” (CURSO DE PEDAGOGIA, 2018, p. 16).

\section{Considerações finais}

O trabalho apresentado neste artigo se constitui numa contribuição social no sentido de complexificar a relação da sociedade contemporânea com a Universidade. As questões explícitas reforçam a relevância da Universidade para a constituição da própria humanidade, pelo seu teor dialético e dialógico, enfrentando as condições unilaterais de cunho mercadológico e, portanto, privatistas, que primam pela formação pautada no Ter em detrimento do Ser.

Se por um lado a nossa discussão torna evidente o peso das condições objetivas, isto é, econômicas e políticas sobre o processo de formação docente, por outro lado também ressaltamos a importância da resistência, ou seja, da luta pela manutenção da autonomia universitária como possibilidade de fortalecimento da formação do espírito, propícia à formação de docentes livres pensantes.

Entretanto, como é esperado, "a questão da emancipação é a rigor um problema mundial” (ADORNO, 2010, p. 174). Desse modo, se torna primordial exercer a resistência por meio da formação cultural, com vistas a problematizar, analisar e tensionar a realidade, a fim de desvelar as contradições sociais, como defende Adorno (2010, p.181), quando se refere a Kant para elucidar que não vivemos numa época esclarecida; mas numa época de esclarecimento. Conclui que "[...] nesses termos ele determinou a emancipação de um modo inteiramente consequente, não como uma categoria estática, mas como uma categoria dinâmica, como um vir-a-ser”.

É importante ressaltar que nossas reflexões insurgem do dialogismo entre os diferentes índices teóricos que constituem as autoras desse artigo, enquanto intelectuais 
e pesquisadoras. Entendemos que foi justamente a partir das diferentes vozes por onde transitam nossos discursos que afirmamos a potência desse enunciado que procurou debruçar-se sobre a razão instrumental e seus desdobramentos nas relações sociais desumanizadoras.

Nesse contexto, as disputas pelo forjamento de currículos comprometidos com os interesses mercadológicos foram confrontadas com o currículo da Universidade Federal Fluminense, mais especificamente, do curso de Pedagogia da Faculdade de Educação- FEUFF, com o qual pudemos demonstrar as possibilidades de enfrentamento do que está posto e naturalizado pela sociedade contemporânea.

Assim, reconhecemos o componente curricular Atividades Culturais como um processo formativo que, ao mesmo tempo realça e extrapola a sala de aula, como um campo fértil para a vinculação entre estudos teóricos e a vida, abrindo outras possibilidades, como poeticamente descrita por Deleuze (1996):

Para mim, uma aula não tem como objetivo ser entendida totalmente. Uma aula é uma espécie de matéria em movimento. É por isso que é musical.

Numa aula, cada grupo ou cada estudante pega o que lhe convém. Uma aula ruim é a que não convém a ninguém.

Não podemos dizer que tudo convém a todos. As pessoas têm de esperar. Obviamente, tem alguém meio adormecido. Por que ele acorda misteriosamente no momento que lhe diz respeito? Não há uma lei que diz o que diz respeito a alguém. $\mathrm{O}$ assunto de seu interesse é outra coisa.

Uma aula é emoção. É tanto emoção quanto inteligência. Sem emoção, não há nada, não há interesse algum. Não é uma questão de entender e ouvir tudo, mas de acordar em tempo de captar o que lhe convém pessoalmente.

É por isso que um público variado é muito importante. Sentimos o deslocamento dos centros de interesse, que pulam de um para outro. Isso forma uma espécie de tecido esplêndido, uma espécie de textura.

Embora tenhamos aqui enfatizado o componente curricular Atividades Culturais, reconhecemos outras possibilidades profícuas no projeto pedagógico do curso de Pedagogia da FEUFF que se contrapõem a uma formação meramente técnica.

Reafirmamos a nossa convicção de que o ambiente da formação de professores na Universidade pública, justamente porque não é controlada diretamente pelo mercado, tem a potência de enfrentar as questões da contemporaneidade sobre a Universidade com profissionalismo e humanidade, ampliando-se as possibilidades da inventividade 
de uma formação cultural que não ignora o mundo do trabalho, mas que se volta, ininterruptamente, para as múltiplas dimensões humanas. Nesse sentido, garantir a autonomia universitária numa sociedade plural, como a nossa, é condição sine qua non para que a própria Universidade possa contribuir no processo de consolidação da democracia.

\section{REFERÊNCIAS}

ADORNO, T. W. Educação e Emancipação. 5a reimpressão. São Paulo: Paz e Terra, 2010.

ADORNO, T. W. Teoria da Semicultura. Primeira Versão, Ano IV. No191. v. XIII. maio/ago. - Porto Velho, 2005.

ADORNO, T. W. \& HORKHEIMER, M. Dialética do Esclarecimento: fragmentos filosóficos. Rio de Janeiro: Zahar, 1985.

AGUIAR, M. A. da S.; DOURADO, L. F. (Orgs.) A BNCC na contramão do PNE 2014-2024: avaliação e perspectivas. [Livro Eletrônico]. Recife: ANPAE, 2018.

BRASIL. Ministério da Educação. Base Nacional Comum Curricular (BNCC). Brasília/DF, 2017. Disponível em: http://basenacionalcomum.mec.gov.br/. Acessado em: 15 maio 2019.

BAUMAN, Z. Medo líquido. Rio de Janeiro: Jorge Zahar Editor, 2008.

BAUMAN, Z. Comunidade: a busca por segurança no mundo atual; tradução Plínio Dentzien. Rio de Janeiro: Jorge Zahar Ed., 2003

BENJAMIN, W. Obras escolhidas I: Magia e Técnica, Arte e Política. São Paulo: Brasiliense, 1994.

CURSO DE PEDAGOGIA. Projeto Pedagógico: estrutura Curricular. Faculdade de Educação (FEUFF) da Universidade Federal Fluminense (UFF). Jun, 2018. Disponível em: http://feuff.sites.uff.br/coordenacao-de-pedagogia/126-2/. Acessado em; 15 maio 2019.

DELEUZE, G. Aula. In: O Abecedário de Gilles Deleuze. TV Escola, Ministério da Educação. Tradução e Legendas: Raccord, 1996.

FOUCAULT, M. História da Sexualidade II.O uso dos prazeres. Rio de Janeiro: Edições Graal,1984.

FOUCAULT, M. A Arqueologia do saber. Rio de Janeiro: Forense, 1986. 
FOUCAULT, M. A ordem do discurso. Laura Fraga de Almeida Sampaio (Trad.). 16. ed. São Paulo: Edições Loyola, 2008.

GALLO, S. Cuidar de si e cuidar do outro: implicações éticas para a educação dos últimos escritos de Foucault. Advir, nº 20, dezembro de 2006, p. 71-9.

GALLO, S. As múltiplas dimensões do aprender. COEB 2012, Congresso de Educação Básica: Aprendizagem e Currículo. Disponível em: http://www.pmf.sc.gov.br/arquivos/arquivos/pdf/13_02_2012_10.54.50.a0ac3b8a14067 6ef8ae0dbf32e662762.pdf. Acessado em: 17 maio 2019.

JAEHN, L. Semi-formação e formação cultural. ETD - Educação Temática Digital,v. 10, n. 1, p. 114-132, 2009. https://doi.org/10.20396/etd.v10i1.1019.

JAEHN, L. Currículo, políticas e regulação social. In: XAVIER, G. T. R. (Org.); JAEHN, L. (Org.); OLIVEIRA, M. L. (Org.). Currículo e Práxis Docente. Niterói: EDUFF, 2014.

KANT, I. Pedagogía. Traducción Lorenzo Luzuriaga e José Luis Pacual. Madrid: Akal, 2003.

LEME, E. S; COSTA, V. A. da. Formação estético-cultural no pensamento de Theodor W. Adorno: a reflexão crítica e o desenvolvimento da sensibilidade. Revista Estética. Universidade de São Paulo - Escola de Comunicações e Artes, v. 2, p. 1 - 14, 2015.

LOPES, A. C. Apostando na produção contextual do currículo. In: AGUIAR, M. A. da S.; DOURADO, L. F. (Orgs.) A BNCC na contramão do PNE 2014-2024: avaliação e perspectivas. [Livro Eletrônico]. Recife: ANPAE, 2018.

MACEDO, E. “A Base é a base”. E o currículo o que é? In: AGUIAR, M. A. da S.; DOURADO, L. F. (Orgs.) A BNCC na contramão do PNE 2014-2024: avaliação e perspectivas. [Livro Eletrônico]. Recife: ANPAE, 2018.

POPKEWITZ, T. S. Reforma educacional: uma política sociológica. Poder e conhecimento em educação. Trad. Beatriz Affonso Neves. Porto Alegre: Artes Médicas, 1997.

POPKEWITZ, T. S. Lutando em defesa da alma: a política do ensino e a construção do professor. Trad. Magda França Lopes. Porto Alegre: Artmed Editora Ltda., 2001.

SANTOS, B. S. Reinventar a Democracia. Cadernos Democráticos, n. 4, Lisboa: Fundação Mário Soares/ Gradiva Publicações Ltda,1998.

SCHILLER, F. A Educação Estética do Homem: numa série de cartas. São Paulo: Iluminuras, 1990.

SCHMIED-KOWARZIK, W. Pedagogia Dialética: de Aristóteles a Paulo Freire. Trad. Wolfgang Leo Maar. São Paulo: Brasiliense S. A. 1983. 
TEIXEIRA, A. Educação e Universidade. Rio de Janeiro: Editora UFRJ, 1988.

VEIGA-NETO, A. Currículo e Cultura. Revista Contrapontos, v. 2, n. 1, 2002.

Disponível em: https://siaiap32.univali.br/seer/index.php/rc/article/view/133/113.

\section{Como referenciar este artigo}

SILVA, Dagmar Mello e; LEME, Erika Souza; JAEHN, Lisete. A universidade pública frente ao contexto contemporâneo: em discussão o currículo e suas possibilidades na formação docente. Revista on line de Política e Gestão Educacional, Araraquara, v. 23, n. esp. 1, p. 766-784, out. 2019. E-ISSN:1519-9029. DOI: https://doi.org/10.22633/rpge.v23iesp.1.13011

Submetido em: 10/05/2019

Revisões requeridas: 14/06/2019

Aprovado em: 10/08/2019

Publicado em: 01/10/2019 